\title{
Capacitive voltage and current induction phenomena in GIS substation
}

\author{
S.M.Hassan.Hosseini ${ }^{1}$, Hamed.Imani ${ }^{2}$, S.M.Hosseini.Bafghi ${ }^{3}$ \\ 1, 2, 3 (Department of Electrical Engineering, Islamic Azad University South Tehran Branch, Tehran, IRAN)
}

\begin{abstract}
Capacitive voltage and current induction is one of the most significant phenomenon's in high voltage GIS substation that the presence of it can impose problems to the substation operation. This paper has simulated the various equipment of $420 \mathrm{kV}$ of Karoon 4 substations such as powerhouses, input and output lines, bus-bar and bus-duct. EMTP-RV software has been used to simulate the equipment. Then with the considering of single-phase and three-phase faults on the line in critical conditions, capacitive voltage and current induction to the power network by parallel capacitor with circuit breaker is surveyed. The results are the maximum values of probable induced current and voltage that can be occurred. The breaker equipment of must be able to interrupt this value of current.
\end{abstract}

Keywords: Gas insulated substation (GIS), induct current, induced voltage

\section{INTRODUCTION}

Parallel capacitors with breaker contacts have been used to improve the performance of power circuit breaker for interrupting the single-phase to ground fault near the circuit breaker in GIS with the voltage rate of $300 \mathrm{KV}$ and above [1]. After a single-phase fault occurs, the return voltage amplitude, which comes from the fault side and can be increased to twice of its nominal value, creates a value of current that the circuit breaker would not be able to interrupt it[2-3]. Parallel capacitor is used to produce a time delay for removing of transient state which is a result of fault. The time delay is determined by the following equation:

$$
t_{d l}=c . z
$$

Where $\mathrm{C}$ is the parallel capacitance with circuit breaker and $\mathrm{Z}$ is the line surge impedance [4-5]. However, the existence of parallel capacitor would produce some problems. A value of voltage and current is induced to the network after the power circuit breaker interruption and due to the capacitor existence.

Disconnect switches must be able to interrupt this value of current. In the paper, this crucial phenomenon has been studied with the modeling of 420 KV Karoon4GIS substation. [1], [4] in previous papers, various methods have been used to model the substation equipment specially bus-bar and bus-duct. Transmission line model with distributed parameters and cable model are some examples of modeled bus-bar and bus-duct in previous papers. Each of these methods has advantages and disadvantages that some of them are mentioned below: [5].

- Ignoring the damping and Losses

- Ignoring dependency of parameters to frequency

- Disregarding the interaction between conductor and enclosure

- The complexity of calculating the parameter in some installing bus bar in bus duct conditions.

The model $\pi$ has been used to model GIS busbar and busduct in this paper due to the Mentioned reasons and the model would be described in detail [4-6].

\section{INTRODUCING OF KAROON4 SUBSTATION}

Karoon4 GIS substation has the voltage rate of $420 \mathrm{KV}$ and double bus-bar arrangement with by-pass disconnect switch. This substation is connected to the power units with 12 additive single-phase transformers in which the capacity of each is $100 \mathrm{MW}$. The substation output is connected to the network with 4 overhead 420 KV lines with double-bundle arrangement. Single-line diagram of mentioned substation has been shown in figure 1. As can be seen, the output lines include: Lordegan double-circuit lines with the length of $48 \mathrm{Km}$ and Karoon3 double-circuit lines with the length of $300 \mathrm{Km}$. 


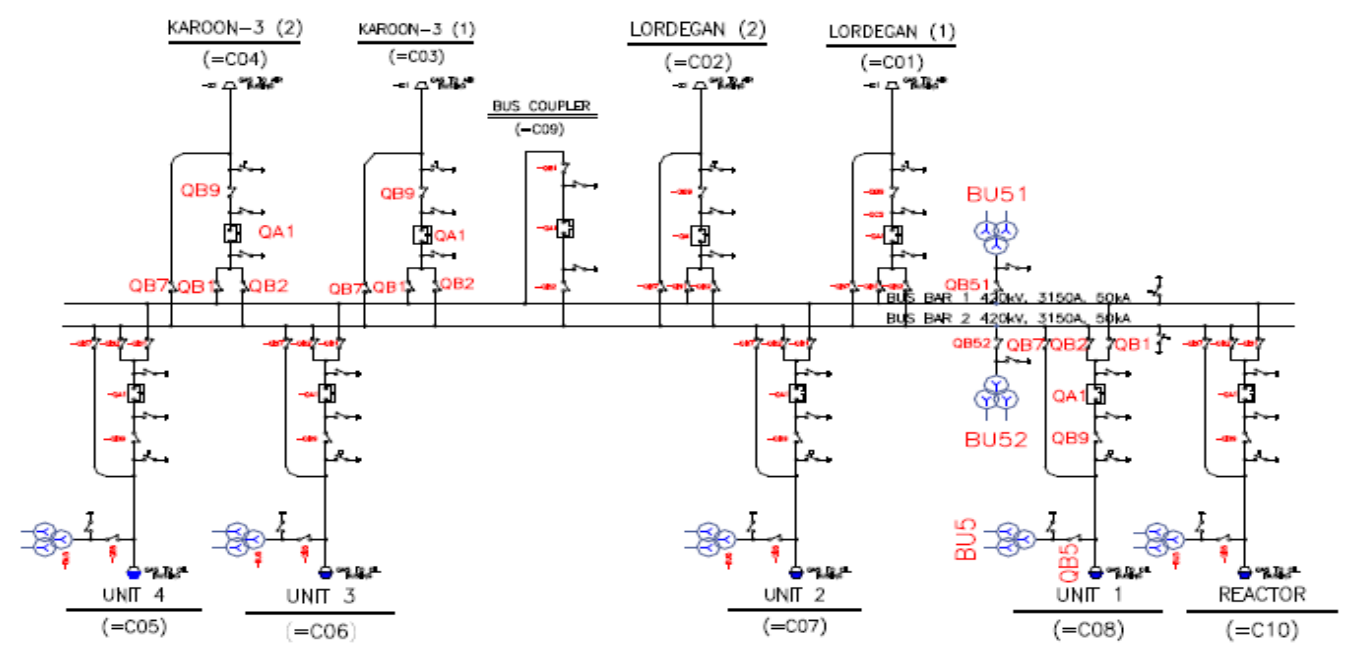

Fig. 1: Single line diagram of KAROON4 420 KV GIS

III. GIS EQUIPMENT MODELING

Bus-bar and bus-duct are some of the effective elements on capacitive voltage and current induction phenomenon in GIS substations. In this paper, double-phase $\pi$ model in EMTP-RV software has been used to model the substation section. In this model, one phase is allocated to bus-bar and the other phase is appropriated to bus-duct (external enclosure). The values of self and mutual inductance and capacitance have been calculated to consider the coupling effect between bus-bar and bus-duct. These values have been put in $\pi$ model. According to the equation 1, the value of mutual capacitance between bus-bar and bus-doct is $43.25^{P F} / \mathrm{m}$. The mutual value of inductance is considered zero. Spacers, also, have capacitance value of $12.26^{P F} / \mathrm{m}$. Equations 2 and 3 have been used to measure the self-capacitance and inductance. [2-4]

$$
\begin{aligned}
& C_{i r}=C_{r\}}=\frac{r \pi \varepsilon^{2} \varepsilon_{s}}{\operatorname{Ln}\left(\frac{a_{i}}{a}\right)} l \quad \mathrm{~F} / \mathrm{m} \\
& \mathrm{C}=\frac{\tau \pi \varepsilon \cdot \varepsilon s}{\operatorname{Ln}\left(\frac{\mathrm{d}}{\mathrm{a}}+\sqrt{\frac{\mathrm{d}^{\top}}{\mathrm{a}^{\tau}}-1}\right)} l \quad \mathrm{~F} / \mathrm{m} \\
& \mathrm{L}=\frac{\mu_{i}}{r_{\pi}} \operatorname{Ln}\left(\frac{a_{1}}{a}\right) l \quad \mathrm{H} / \mathrm{m}
\end{aligned}
$$

Where $d$ is the distance between enclosure center and ground, a is external radius, $a$, is internal radius and 1 is length of enclosure. The double-phase $\pi$ model, which has been used in this paper, is shown in figure 2 . A series model of inductor with resistor has been used for reactor and, surge arresters have also been modeled as non-linear resistance. FD model was used in the purpose of transmission lines modeling.

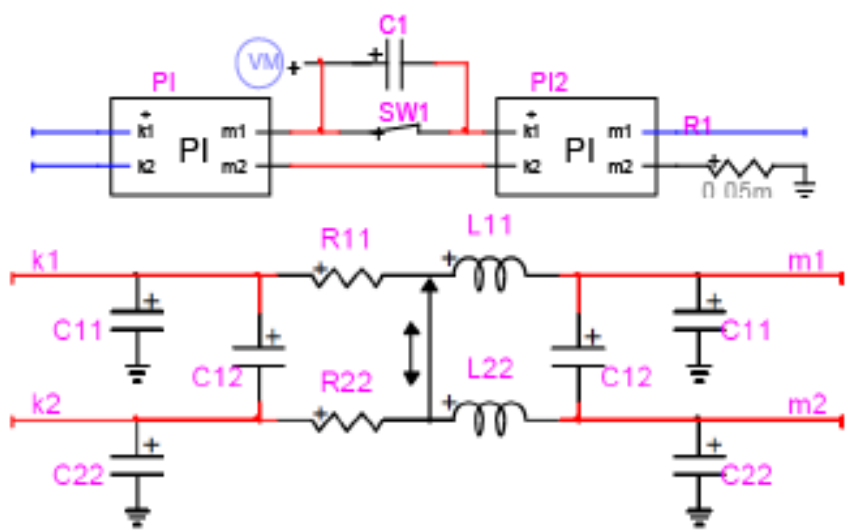

Fig. 2: $\pi$ Equivalence Model for GIS busbar and busdact The transmission line arrangement is shown in figure3. 


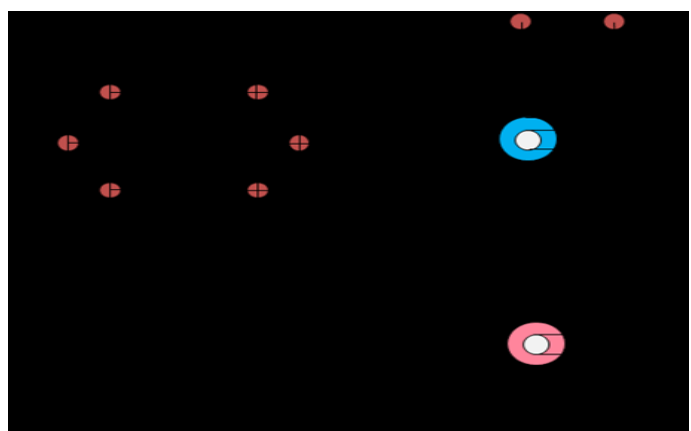

Fig. 3: The transmission line arrangement

IV.

SIMULATION RESULTS

In this section, first, the network is considered in no-fault condition. The generators are disconnected from the network and the network is supplied form the line side. When the line side circuit breaker is opened, a value of voltage is transferred to bus-bar through a capacitor which is paralleled with circuit breaker. The voltage value that is produced on bus-bar will be less than the primary voltage due to the voltage division between circuit breaker capacitor, other circuit breakers and the coupled capacitor which between GIS and ground. When the circuit breaker is opened, a value of current is also induced to the network due to the existence of a capacitor which is paralleled with the circuit breaker contact. The current and voltage values are similar to the measured value during launching the substation. These values are shown in figures 4 and 5 . Thereafter, the fault current value and capacitive voltage and current induction phenomena are presented in different fault conditions.

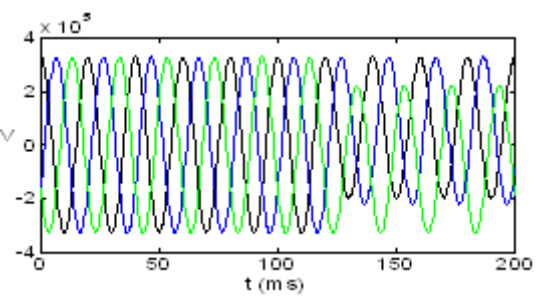

Fig. 4: Induced current with no fault condition (A-mS)

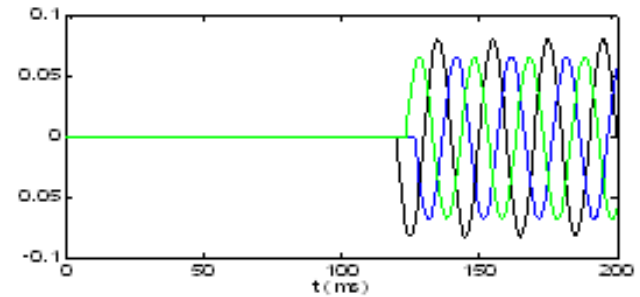

Fig. 5: Induced voltage with no fault condition $(\mathrm{V}-\mathrm{mS})$

V.

\section{SINGLE-PHASE TO GROUND FAULT ON TRANSMISSION LINE}

There is a single-phase to ground fault at $10 \mathrm{~ms}$ in $26.6 \mathrm{Km}$ away from the beginning of Karoon 3 line then the begin and end circuit breakers of the line start interrupting the line from the network at $120 \mathrm{~ms}$. This event has been simulated and the fault current waveform is shown in figure 6 . As can be seen, the value of fault current pick is $51 \mathrm{kA}$. A value of current is passed through the parallel capacitor with circuit breaker due to the interrupting of begin and end circuit breakers of the line and it is induced to the network. This induced current is shown in figure 7 . As it is clear, the current value reaches to 0.41 amperes in steady state. The induced voltage value is completely similar to the measured value in the substation. This value is shown in figure 8 .

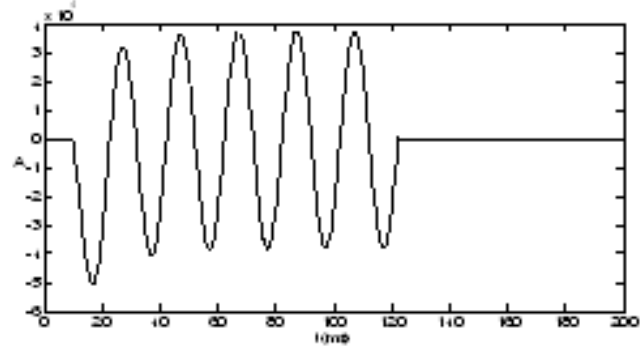

Fig. 6: Single-phase to ground fault current on transmission line (A-mS) 


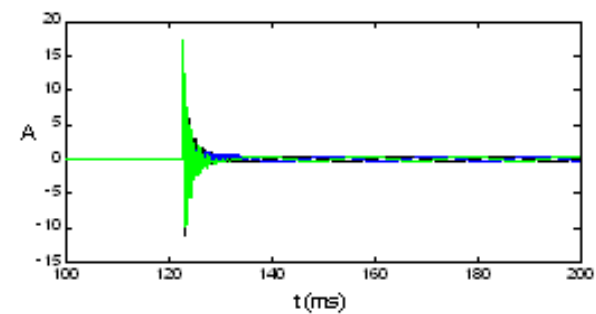

Fig. 7: Induced current to the network after single-phase to ground fault removing (A-ms)

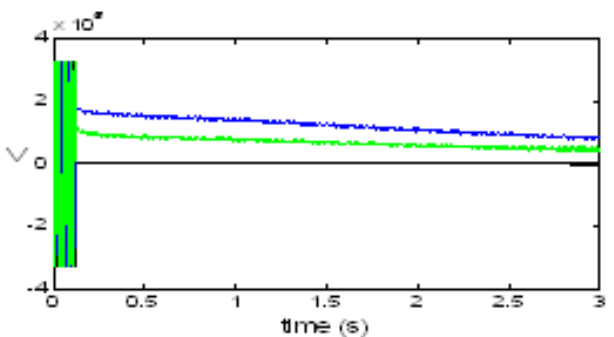

Fig. 8: Induced voltage to the network after single-phase to ground fault removing (V-ms)

\section{THREE-PHASE TO GROUND FAULT ON TRANSMISSION LINE}

A three-phase short-circuit fault occurs at $10 \mathrm{~ms}$ in $26.6 \mathrm{Km}$ away from Karoon3 line outset. The begin and end circuit breakers of the line interrupt the line form the network at $120 \mathrm{~ms}$ This event has been simulated and the fault current waveform is shown in figure 9. As can be seen, the fault current pick value is $64 \mathrm{kA}$. A current value is passed through parallel capacitor with circuit breaker due to the interruption of begin and end circuit breakers of the line. Then, this current value is induced to the network that is shown in figure 10. As can be seen, the current value reaches to 0.48 amperes in steady state. The induced voltage is, also, shown in figure 11. As it is clear form figure 11 , the obtained voltage value is quite similar to the measured value of the substation. The results in different conditions are shown in table 1.

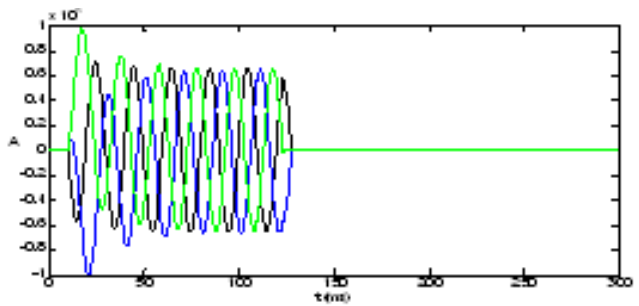

Fig. 9: three-phase short-circuit fault current on transmission line (A-ms)

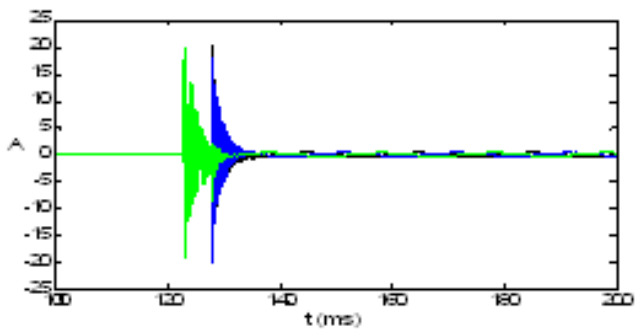

Fig. 10: Induced current to the network after three-phase short-circuit fault removing (A-ms)

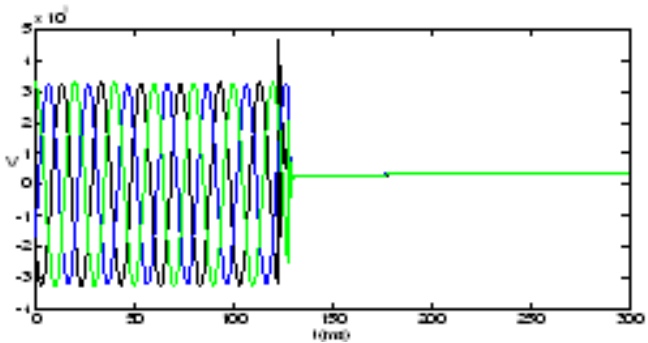

Fig. 11: Induced voltage to the network after three-phase short-circuit fault removing (V-ms) 
Table 1: Calculation summary of induced current and voltage in different conditions

\begin{tabular}{|c|c|c|c|}
\hline \multicolumn{2}{|c|}{ CB capacitor } & \multicolumn{2}{|c|}{$4000 \mathrm{pF}$} \\
\hline \multirow{2}{*}{ Nault Case } & Initial & Steady \\
\hline \multirow{2}{*}{$\begin{array}{c}\text { Single-phase } \\
\text { to Ground }\end{array}$} & $\begin{array}{c}\text { Induced } \\
\text { Current [A] }\end{array}$ & 0.08 & 0.08 \\
\cline { 2 - 4 } & $\begin{array}{c}\text { Induced } \\
\text { Voltage[kV] }\end{array}$ & 327 & 262 \\
\cline { 2 - 4 } Induced & $\begin{array}{c}\text { Induced } \\
\text { Voltage[kV] }\end{array}$ & 230 & 9.2 \\
\hline \multirow{2}{*}{$\begin{array}{c}\text { Three-phase } \\
\text { short-circuie }\end{array}$} & $\begin{array}{c}\text { Induced } \\
\text { Current [A] }\end{array}$ & 21 & 0.48 \\
\cline { 2 - 4 } & $\begin{array}{c}\text { Induced } \\
\text { Voltage[kV] }\end{array}$ & 467 & 2.1 \\
\hline
\end{tabular}

VII.

VERIFICATION

In this section, two cases of obtained results from the presented model of this paper have been compared to the producer results and the verification of presented model is confirmed. Figure 12, which has been provided by producer, is shown the induced current that is due to circuit breaker interruption for singlephase fault current removing on the line.

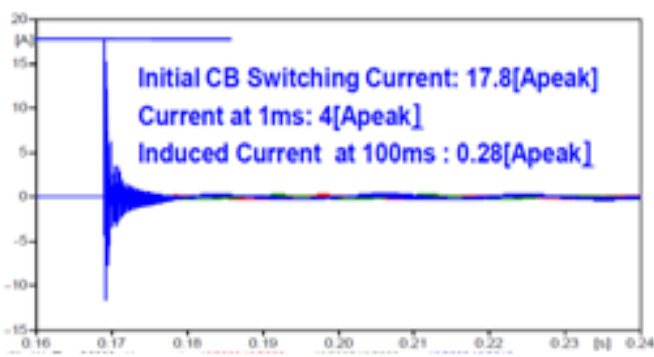

Fig. 12: Induced current presented by manufacturer after single-phase to ground fault removing

As it is clear, the obtained result of presented model of this paper is similar to the presented result of producer. Figure 13, which has been provided by producer, is shown the induced current that is due to circuit breaker interruption for three-phase short-circuit fault current removing on the line.

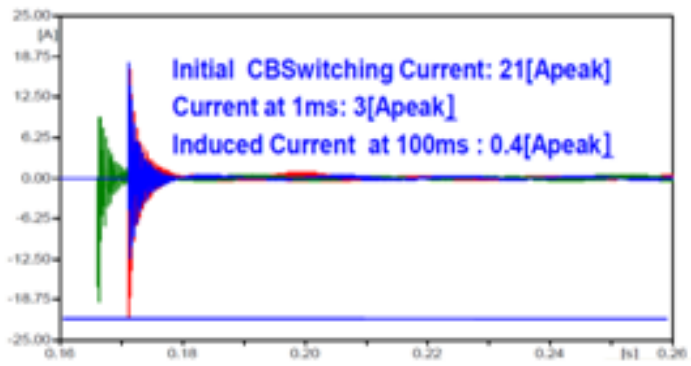

Fig. 13: Induced current presented by manufacturer after three-phase short-circuit fault removing

In this case, as it is clear, the obtained result of presented model of this paper is also similar to the presented result of producer. The obtained results of this section confirm the verification of presented model so it validates all results.

\section{CONCLUSION}

In this paper, capacitive current and voltage induction phenomena in $420 \mathrm{KV}$ Karoon4 GIS substation were studied and simulated in EMTP-RV software. As it was seen, with the interrupting of all kinds of faults, a value of current, (which was called induced current) passed through the parallel capacitor with circuit breaker in this substation. In this case, a value of voltage, also, was induced to one side of capacitor which was located in line side. The results indicate that the value of remnant current, which is due to parallel capacitor and coupled capacitor of system with the ground, cannot exceed 0.5 amperes for all conditions. So the disconnect switches 
that are used in the substation must be able to interrupt this current value. However, it must be considered that the results were obtained in the worst conditions and these conditions must be noticed during the testing and designing of equipment. The complexity of capacitive current and voltage induction phenomena in high voltage GIS substation were shown in this research. Consequently, in order to design and appropriate choose of disconnect switch, studying about this phenomenon is an essential issue so that without having enough knowledge, the substation operation would face with problem.

\section{REFERENCES}

[1] Kumar, V.V., J.M. Thomas, M.S. Naidu, 2001 Influence of switching conditions on the VFTO magnitudes in a GIS, IEEE Trans, Power Delivery, 16, 539-544.

[2] Kondalu, M., Gillella Sreekanth Reddy, Dr.P.S.Subramanyam, 2001. Estimation of Transient over Voltages in Gas Insulated busduct from $220 \mathrm{kv}$ Gas Insulated Substation, International Journal Computer Applications (0975 - 8887).

[3] Liu, Qing, Yufeng Zhang, 2008. Influence of Switching Conditions on Very Fast Transient Over-voltage in500kV Gas Insulated Substation, Department of Electrical and Control Engineering of Xi'an University of Science and Technology, Xian, China, 710054.

[4] Switching Capability of $420 \mathrm{kV}$ Disconnecting Switch, Hyundai Heavy Industrial Co. LTD, Electro Electri System Div. /ElectroMechanical Research Institute, , November 2011.

[5] Tavakoli, A., A. Gholami, A. Parizad, H.M. Soheilipour, H. Nouri2009. Effective Factors on the Very Fast Transient Currents and Voltage in the GIS, T \& D, Asia and Pacific, October 26-30.

[6] Thompson, 1999. Inductance Calculation Teqnique-Approximations and Handbook Methods, Power Control and Intelligent Motion, 25: $40 \_45$. 